\title{
Evaluation of various factors in secondary infertility by diagnostic laparoscopy
}

\author{
Rekha N. ${ }^{1}$, Shashikala B. Patil ${ }^{2 *}$
}

\begin{abstract}
${ }^{1}$ Department of Obstetrics and Gynecology, BGS Global Institute of Medical Sciences, Bangalore, Karnataka, India ${ }^{2}$ Department of Obstetrics and Gynecology, Bangalore Medical College and Research Institute, Bangalore, Karnataka, India
\end{abstract}

Received: 28 February 2017

Accepted: 31 March 2017

\section{*Correspondence:}

Dr. Shashikala B. Patil,

E-mail: drshashika@gmail.com

Copyright: ( ) the author(s), publisher and licensee Medip Academy. This is an open-access article distributed under the terms of the Creative Commons Attribution Non-Commercial License, which permits unrestricted non-commercial use, distribution, and reproduction in any medium, provided the original work is properly cited.

\section{ABSTRACT}

Background: Infertility is defined as one year of unprotected conception. It affects approximately 10-15\% of couples in reproductive age group. Secondary infertility implies that at least one previous pregnancy has occurred, regardless of the outcome. Of the various factors responsible, the brunt of the problem in secondary infertility is born by tuboperitoneal factor, ovulation factor, uterine factor and past obstetric outcomes. This lead to the emergence of diagnostic laparoscopy for evaluation of pelvic pathology in secondary infertility. The objective of the study was to secondary infertility by diagnostic laparoscopy is undertaken for following purpose. Evaluation of different causes using laparoscopy. Detecting the commonest cause of secondary infertility in our place of study.

Methods: This study was conducted in the Department of Obstetrics and Gynaecology at 50 married women who presented with secondary infertility at the outpatient department Sri Adichunchanagiri Hospital and Research Centre, B.G nagar, Mandya district were recruited in this study. Study was done for 2 years. Detailed clinical history with respect to duration and nature of infertility, detailed menstrual history, past obstetric history, a complete medical, surgical and gynaecological history, medications, sexual history, personal history and habits, details of previous tests and therapy for infertility if any taken. Patients were subjected to a general physical, abdominal and pelvic examination to detect any obvious pathology. The laparoscopic procedure was planned in the premenstrual period. With the help of the laparoscope, the pelvic organs are visualized and studied. Chromopertubation done with methylene blue. Later dilatation and currettage done and endometrium sent for HPE.

Results: Most common age group was 25-29 years. There were 27 Cases (54\%) of secondary infertility. In our study, the cases recruited for diagnostic laparoscopy had to be infertile for a minimum period of 12 months, following their recent past obstetric outcome. 23 cases $(50 \%)$ of secondary infertility had a duration between 7-9 years. Of the 50 cases of secondary infertility, 24 cases $(48 \%)$ had definite tubal involvement. Of the 50 cases of secondary infertility, 8 cases $(16 \%)$ had ovarian involvement. In our study, tubal factors contributed largely to infertility as evidenced by the fact that it was present in 24 cases $(48 \%)$. This is followed by peritoneal factor in 10 cases $(20 \%)$. Ovarian factor in 8 cases $(16 \%)$ and uterine factor in 5 cases $(10 \%)$.

Conclusions: Diagnostic Laparoscopy is now a universally accepted procedure for evaluating the intraperitoneal and peritubal causes of infertility in the female. The work up of every secondary infertile female must involve a laparoscopic evaluation after meticulously excluding the male factor.

Keywords: Causes, Laparoscopy, Secondary infertility 


\section{INTRODUCTION}

Women, traditionally have been raised to view motherhood as their primary adult role. The depressing problem of infertility is perhaps as old as life itself on this earth.

Conception often deemed to be a relatively simple process is usually an extremely complex one and results due to fertilization of ova by the sperm and fertilized ovum should be implanted and supported by an adequately functioning corpus luteum. Various factors like hormonal events associated with follicular maturation, ovulation, corpus luteum formation complemented by the anatomical factors, cervical factors, tubal factors and peritoneal factors are of immense importance.

Infertility is defined as one year of unprotected conception. It affects approximately $10-15 \%$ of couples in reproductive age group. ${ }^{1}$

Primary infertility if the one in which no previous pregnancies have occurred.

Secondary infertility is defined in various aspects.

- Secondary infertility implies that at least one previous pregnancy has occurred, regardless of the outcome. ${ }^{2}$

- It is also defined as the history of conception at least once in the current partnership. ${ }^{3}$

Resolve-national fertility association states that 3 million couples are unable to conceive for the second time. ${ }^{4}$ National Survey of Family Growth estimates an increase in the number of infertile women from 5-6.3 million to 6.4-7.7 million by $2025 .^{5}$ Fecundability is defined as probability of conceiving during the first cycle and is 20$25 \%$ per cycle. $^{6}$

Time required for conception in couples. ${ }^{6}$

$\begin{array}{ll}3 \text { Months } & 57 \\ 6 \text { Months } & 72 \\ 12 \text { Months } & 85 \\ 18 \text { Months } & 93\end{array}$

The basis for evaluation of secondary infertility is:

- Even if a couple have previously proven fertility, various factors changes with time, Ex: Fertility declines with age.

- To reach a diagnosis swiftly and provide appropriate management.

- The emergence of secondary infertility can challenge even the strongest of marriages that can lead to distancing and alienation within the relationship.

Of the various factors responsible, the brunt of the problem in secondary infertility is born by tuboperitoneal factor, ovulation factor, uterine factor and past obstetric outcomes. This lead to the emergence of diagnostic laparoscopy for evaluation of pelvic pathology in secondary infertility.

Laparoscope affords the gynaecologist a marvelous advantage of making precise diagnosis by evaluating all factors of infertility like ovarian, tubal and peritoneal factors.

The objective of the study was to secondary infertility by diagnostic laparoscopy is undertaken for following purpose. Evaluation of different causes using laparoscopy. Detecting the commonest cause of secondary infertility in our place of study.

\section{METHODS}

This study was conducted in the Department of Obstetrics and Gynaecology at 50 married women who presented with secondary infertility at the out-patient department Sri Adichunchanagiri Hospital and Research Centre, B.G nagar, Mandya district were recruited in this study. Study was done for 2 years.

Detailed clinical history with respect to duration and nature of infertility, detailed menstrual history, past obstetric history, a complete medical, surgical and gynaecological history, medications, sexual history, personal history and habits, details of previous tests and therapy for infertility if any taken. Patients were subjected to a general physical, abdominal and pelvic examination to detect any obvious pathology.

Investigation like $\mathrm{Hb}$ percentage, TC, DC ESR, urine examination, screening of chest, RBS, Mantoux test and ultrasound, semen analysis of male partners was performed on the patients. Informed consent was obtained for the procedure. Preanaesthetic checkup done prior to laparoscopy.

The laparoscopic procedure was planned in the premenestrual period. With the help of the laparoscope, the pelvic organs are visualized and studied. Chromopertubation done with methylene blue. Later dilatation and currettage done and endometrium sent for HPE.

\section{Inclusion criteria}

- Reproductive age group

- Proven past fertility

- Infertility of minimum one year duration

\section{Exclusion criteria}

- Primary infertility

- Tubectomy

- IUCD, Oral pill users

- Male infertility 
- Premature ovarian failure

- Acute pelvic or vaginal infections

- Extreme obesity

- Any medical/Surgical disorders contraindicating laparoscopy.

\section{RESULTS}

Table 1: Distribution of cases with respect to age.

\begin{tabular}{|lll|}
\hline Age (years) & Secondary infertility \\
\hline & Cases & Percentage \\
\hline$<25$ & 2 & 4 \\
\hline $25-29$ & 27 & 54 \\
\hline $30-34$ & 16 & 32 \\
\hline$>35$ & 5 & 10 \\
\hline
\end{tabular}

On distributing the cases with respect to age, we found that: 27 Cases $(54 \%)$ of secondary infertility belonged to age group $25-29$ years. 16 cases $(32 \%)$ of secondary infertility belonged to 30-34 years' age group. 5 cases $(10 \%)$ and 2 cases $(4 \%)$ of secondary infertility belonged to age group of $>35$ years and $<25$ years aged group, respectively.

Table 2: Duration of secondary infertility.

\begin{tabular}{|lll|}
\hline Duration (years) & \multicolumn{2}{l|}{ Secondary infertility } \\
\hline $1-3$ & Cases & Percentage \\
\hline $4-6$ & - & - \\
\hline $7-9$ & 17 & 34 \\
\hline 10 & 28 & 56 \\
\hline
\end{tabular}

In our study, the cases recruited for diagnostic laparoscopy had to be infertile for a minimum period of 12 months, following their recent past obstetric outcome.

None of the cases of secondary infertility had a duration varying from 1-3 years. 23 cases $(50 \%)$ of secondary infertility had a duration between 7-9 years. 17 cases $(34 \%)$ and 5 cases $(10 \%)$ were infertile for 4-6 years and $>10$ years respectively.

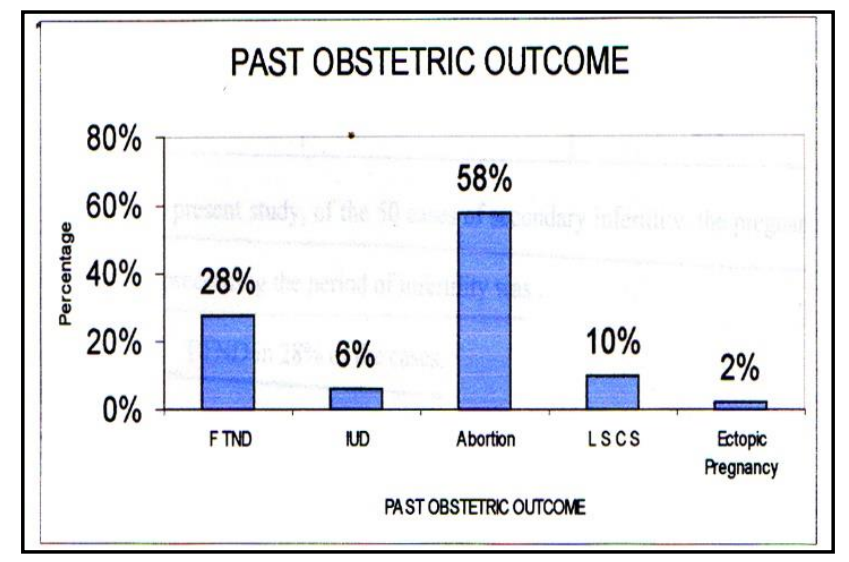

In the present study, of the 50 cases of secondary infertility, the pregnancy immediately preceding the period of infertility was:

- FTND in $28 \%$ of the cases.

- IUD in $6 \%$ of the cases

- Abortion in $58 \%$ of the cases

- Caesarean section in $10 \%$ of the cases.

- Ectopic pregnancy in $2 \%$ of the cases.

Factors contributing to secondary infertility. The details of various factors contributing to infertility that were detected by Laparoscopy.

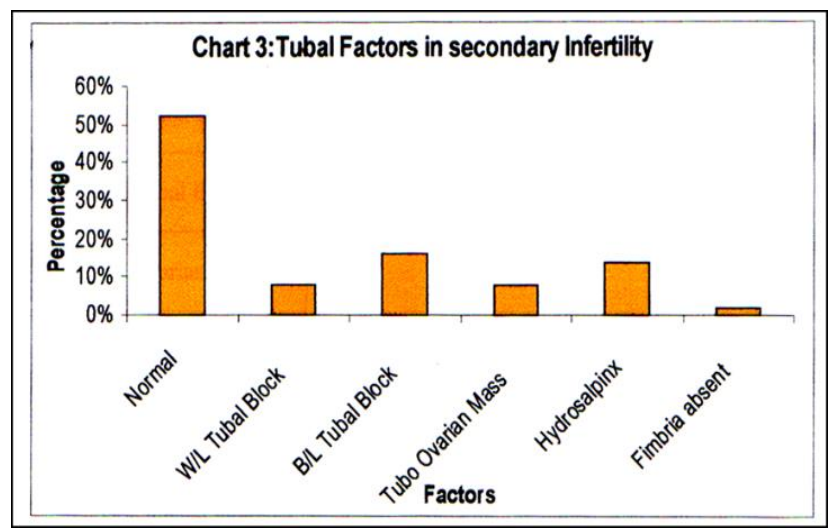

Figure 2: Tubal factors.

Of the 50 cases of secondary infertility, 24 cases $(48 \%)$ had definite tubal involvement. Of these 4 cases (8\%) had unilateral tubal block, 8 cases $(16 \%)$ had bilateral tubal block, 4 cases $(8 \%)$ had tuboovarian mass, 7 cases $(14 \%)$ had hydrosalpinx. 1 Case with past history of ectopic had unilateral fimbria absent due to past surgery.

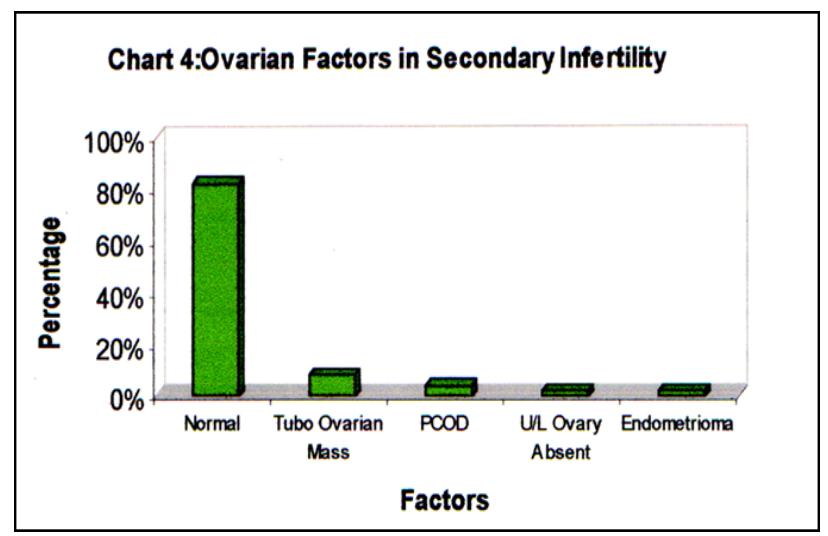

Figure 3: Ovarian factors.

Of the 50 cases of secondary infertility, 8 cases $(16 \%)$ had ovarian involvement. Of these 2 cases $(4 \%)$ had PCOD, 4 cases (8\%) had tubo ovarian mass, 1 case, $(2 \%)$ each of enometrioma and an absent ovary (Surgery for past ectopic) were present.

Figure 1: Past obstetric outcome. 
Of the 50 cases of secondary infertility, 10 cases (20\%) had peritoneal involvement, 8 case $(16 \%)$ had adhesions and 2 cases $(4 \%)$ had endometriosis. Of the 50 cases of secondary infertility, 5 cases $(10 \%)$ had uterine involvement. 1 case $(2 \%)$ had retroverted uterus, 3 cases (6\%) had fibroid and 1 case had arcuate uterus.

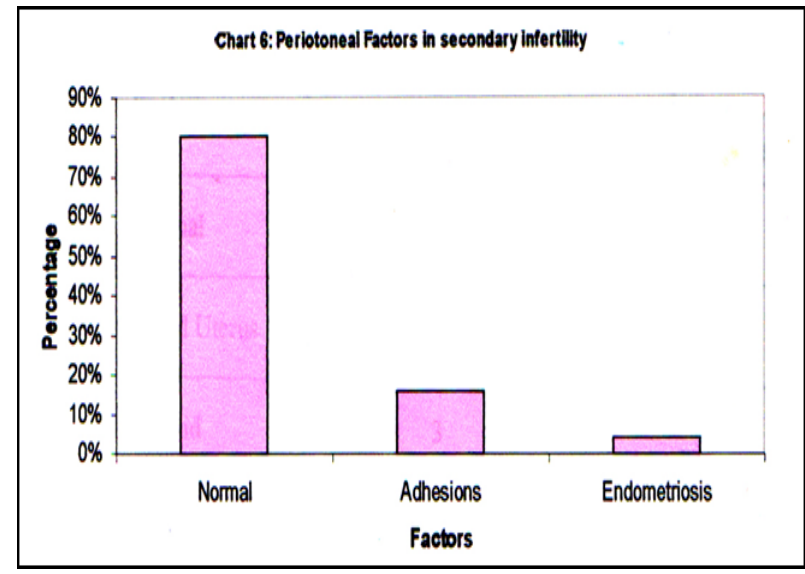

Figure 4: Peritoneal factors.

The Chromopertubation was performed in all 50 patients. The observation was as follows: Normal, healthy, patent tubes in 23 cases (46\%), 17 cases (34\%) had unilateral tubal block and 10 cases $(20 \%)$ had bilateral tubal block. Assessment of endometrial character is important since it may indicate the hormonal mileu and assessment of ovarian and hypothalmo pituitary function.

Diagnostic dilatation and currettage was performed at the end of the procedure. The histopathological reports obtained with respect to endometrium showed secretary endometrium in 46 cases $(92 \%)$ followed by proliferative endometrium in 4 cases $(8 \%)$.

Table 3: Various factors contributing to secondary infertility.

\begin{tabular}{|lll|}
\hline Factors & \multicolumn{2}{l|}{ Secondary infertility } \\
\hline Cases & Percentage \\
\hline Tubal & 3 & 6 \\
\hline Ovarian & 24 & 48 \\
\hline Uterine & 8 & 10 \\
\hline Peritoneal & 5 & 10 \\
\hline
\end{tabular}

In our study, tubal factors contributed largely to infertility as evidenced by the fact that it was present in 24 cases $(48 \%)$. This is followed by peritoneal factor in 10 cases $(20 \%)$. Ovarian factor in 8 cases $(16 \%)$ and uterine factor in 5 cases $(10 \%)$.

As stated of the 50 cases studied, 34 cases $68 \%$ were assessed to be clinically normal and 16 cases $(32 \%)$ were clinically abnormal. Laparoscopic examination revealed normal findings in 3 cases $(6 \%)$ and 47 cases $(94 \%)$ had abnormal findings.

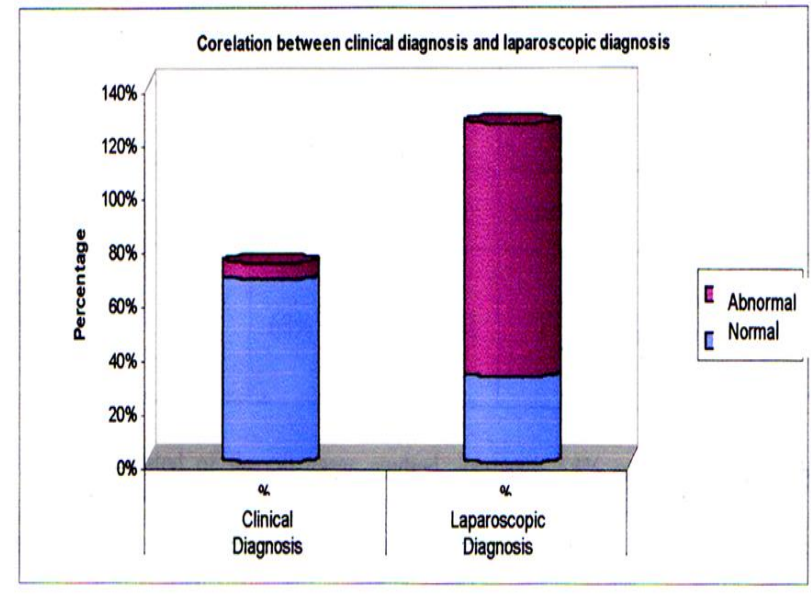

Figure 5: Correlation between clinical diagnosis and laparoscopic diagnosis.

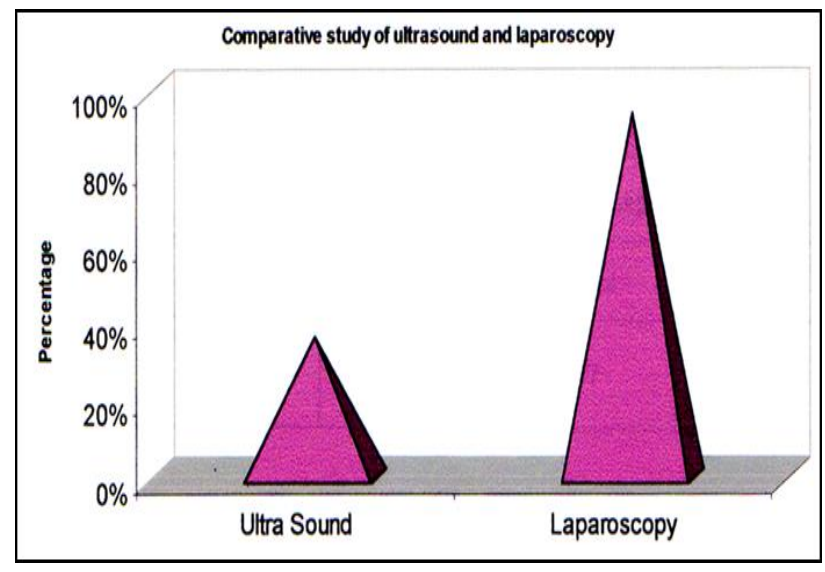

Figure 6: Comparative study of ultrasound and laparoscopy.

All the patients recruited for the study had an ultrasonography prior to Diagnostic laparoscopy. Of the total 50 cases examined, 18 cases $(36 \%)$ were declared to have abnormal USG findings. After Laparoscopic visualization, 47 cases (94\%) has abnormal findings.

\section{DISCUSSION}

Laparoscopy was selected in our study to evaluate the secondary infertile patients in our rural setup. The procedure is time saving, assures accurate diagnosis with direct visualization of internal genital organs in the female-as put forth by Streptoe.

Since Kalk in 1929 developed laparoscopy, as an effective diagnostic procedure, it has been widely used to visulize the pelvic organs particularly, in cases of infertility. ${ }^{8}$ Infertility ranks first, amongst the indications for diagnostic laparoscopy in infertility, accounting to $55.5 \% .^{9}$ 
Cases with secondary infertility were selected in our study as some of the problems encountered affected the outcome and marital harmony.

Laparoscopy was used as a diagnostic modality which was time saving, required minimal duration of inpatient stay and most of the causes of infertility could be assessed in a single sitting.

The analysis and focused on the common causes of secondary infertility and the efficacy of laparoscopy in the diagnosis of secondary infertility.

In the present study, majority of the patients of secondary infertility belonged to the age group 25-29 years.

Age is a major factors and fertility rates have been shown to decline with age of the according to Krishna Menon, the cumulative female fertility decreases after 30 years of age. Collins J.A. considers the age of the female partner as a prognostic factor in prolonged unexplained infertility. ${ }^{10}$

In addition to the inherent efforts of age on the reproductive organs, advancing age increases the interval of time available for exposure to diseases with potentially damaging effects on fertility, including endometriosis, STDs and PID. ${ }^{11}$ Hence there is decline of fertility with advantage age.

In the present study, majority of patients of secondary infertility-58\% had a duration of infertility of 7-9 years, which correlated with the study conducted by Guleri et. al. and Sinha et. Al.

Hutchins C J states, that women over 30 years of age, infertility of 3 or more years of duration should directly undergo laparoscopy after the initial evaluation is complete. $^{12}$ Approximately $80 \%$ of the married couples initiate pregnancy within 12 months of attempting to achieve a pregnancy and about $90 \%$ within 2 years (Moghissi). ${ }^{13}$ Hence duration of infertility influences the successful outcome in treatment of infertility.

In the present study, among 50 cases secondary infertility following an abortion is greater than any other obstetric outcome.

According to $\mathrm{WHO}$, one of the major cause of infertility in developing countries is pot-abortal and post-partum infections leading to tubal blockages.

Goldman detected the occurrence of either induced abortion or spontaneous abortion independently and significantly increased the risk of subsequent development of secondary infertility. ${ }^{14}$

The common laparoscopic findings in past history of abortion is found to be adhesions and distal tubal occlusion. ${ }^{15}$
In the present study, ovarian factors were present in $18 \%$ of the secondary infertility cases, which correlated with the study conducted by Daftary et al. and Hamid et al. who found ovarian factors in $15.4 \%$ and $25 \%$ of secondary infertility cases, respectively.

Laparoscopy promotes direct visualization of ovaries and helps in accurate diagnosis of periovarian adhesions and Ovarian endometriomas. It has equal importance as ultrasonography in the diagnosis of PCOD and also allows therapeutic manipulation. ${ }^{16}$

In the present study, uterine factors were present in $10 \%$ of secondary infertility cases which correlated with the study conducted by Goel et al. and Daftary et al. who detected uterine factors in $11.2 \%$ and $11.7 \%$ of secondary infertility cases respectively.

In the present study, peritoneal factors were present in $20 \%$ of secondary infertility cases.

Goel et.al., Daftery et al. and Hamid et al. found peritoneal factors in $19.85 \%, 19.2 \%$ and $20 \%$ of secondary infertility cases.

Pelvic Inflammatory disease leading to pelvic adhesions and tubal occlusion is the most significant pathology in infertility, especially in developing countries, according to National Representative Demographic and Health Survey.

According to Gibson et.al. of the women in age group 2534 years, $19.2 \%$ were rendered infertile after one episode of PID. This value increased to $31 \%$ and $60 \%$ for II and III episodes respectively. ${ }^{17}$

Pelvic Inflammatory Disease and Endometriosis-2 common causes of infertility of unexplained origin, are accurately diagnosed by Laparoscopy. ${ }^{18}$

Of the 50 cases of secondary infertile, $34 \%$ had unilateral tubal block, and $20 \%$ had bilateral tubal block. The results correlated with the study of Kumari et al. who reported $31.3 \%$ of unilateral tubal block and $18.95 \%$ of bilateral tubal block and that of Bhatia et.al. who reported $29.6 \%$ of unilateral tubal block and $22 \%$ of bilateral tubal block.

Laparoscopy with chromopertubation is considered the standard for evaluating tubal pathology. Chromopertubation in addition to detection of tubal patency, breaks small endosalpingeal adhesions. ${ }^{19}$ The false negative results due to cornual spasm during HSG can be avoided during laparoscopy under general anaesthesia. ${ }^{20}$

In the present study, abnormal laparoscopic findings were present in $94 \%$ which correlated with the study conducted by Sellors et al who found abnormal laparoscopic findings in $99.2 \%$ 
Laparoscopy reigned superior to clinical examination in endometriosis, and pelvic adhesions. Improved visualization of the fallopian tube is a major advantage of laparoscopic investigation. ${ }^{21}$ In the present study ultrasonography detected abnormalities in $36 \%$ of secondary infertility cases and laparoscopy detected abnormalities in $94 \%$ of the cases. Our study correlated with the results of Pratap et.al. who found that $35.8 \%$ cases could be detected by USG in infertility.

In our study of 50 cases of secondary infertility, tubal occlusion and associated tubal factors like peritubal adhesions as a consequence of Pelvic inflammatory disease accounted for majority of the infertility cases similar to study Ashok kumar $\mathrm{K}$ et al. ${ }^{21}$ Hence tubal pathology following pregnancy termination culminating into pelvic inflammatory disease is the most common factor of secondary infertility in our study. This analysis is supported by the fact that developing countries like China, Pakistan and India have increased incidence of PID, which affects the fertility process. In the present series, no major complication was encountered going by the American Association of Gynaecology Laparoscopists (AAGL) definition of major complications. This could probably be accounted for by the fact that relatively small number of cases were studied in this series.

\section{CONCLUSION}

Diagnostic Laparoscopy is now a universally accepted procedure for evaluating the intraperitoneal and peritubal causes of infertility in the female. The work up of every secondary infertile female must involve a laparoscopic evaluation after meticulously excluding the male factor. The liberal use of laparoscopy is encouraged in infertile patients despite the absence of historic factors that might suggest tubal disease. Moreover, the silent nature of PID as well as its increased prevalence within our society, makes new efforts at surveillance and treatment mandatory. Our study concludes tubal factor due to pelvic inflammatory disease as the commonest cause of secondary infertility by diagnostic laparoscopy. Hence, health education regarding barrier contraception, signs and symptoms of pelvic inflammatory disease and measures to adopt post abortal and post-partum hygiene should be promoted.

Hence laparoscopy can be recommended as the most sensitive and accurate diagnostic measure for the assessment of etiology of infertility.

Funding: No funding sources

Conflict of interest: None declared
Ethical approval: The study was approved by the Institutional Ethics Committee

\section{REFERENCES}

1. Janathan S. Berek MD. Novak's Gynecology- MMSc, Thirteenth Edition. Infertility; 974.

2. Jeffcoate's Principles of Gynaecology-International Edition-5th Edition-Infertility and Assisted Reproductive Technology; 644.

3. Kliger-Infertility evaluation-Fertil and Steril. 1984;41(1):41.

4. Clinical Obstetrics and Gynaecology-Williams and Wilkins, Contemporary Management of Infertility. 1977;43(4):172.

5. Daily Health Reproductive Report; 2003:15.

6. Speroff L, Glass RH, Kase NG. Female infertility Clinical Endocrinology and Infertility, $5^{\text {th }}$ Edition. 1994;816-7.

7. Streptoe. A new method of tubal sterilization. 1978; 38(1);133.

8. Fewis H, Frangoenheim. Textbook of Gynaecological Endoscopy Gordon, -History of Endoscopy, 1.2-1.3.

9. Golditch IM-Laparoscopy: Advances and advances. Fertil and steril. 1971;22(5):306-10.

10. John A. Collins: The better prognosis in secondary infertility is associated with ovulation disorders. Fertil and Steril. 1986;45(5):611.

11. Jacobson and Westrom L: Objectivised diagnosis of Pelvic Inflammatory Disease, Am J of obstet and Gynaic.1969:105;1088.

12. Hutchins CJ-Laparoscopy and HSG in the assessment of tubal patency, Obstet Gynecol. 1977; 49:325.

13. Kistner's Textbook of Gynaecology-Principles and Practice, $6^{\text {th }}$ Edition, Evaluation of Infertile Couple. 1995;297-8.

14. Goldman M. Journal of Epidemiology and Community Health. 1998;47:36-9.

15. WHO-Infections, Pregnancies and Infertility- Fertil and Steril. 1987;47(6):964-5.

16. Palmer R. Les enplorations Fanctionellers Gynaecologiques, Paril. 1963;375.

17. Gibson. Patterns of adnexal damage. Fertil and Steril. 1984;41(1).

18. Tripathy SN. Laparoscopic Observations of Pelvic Organs in Pulmonary tuberculosis mt. J. of Obstet and Gynaec. 1990;32(3);129-31.

19. Daftary SN, Sheiriar NK. Combined Laparo Hysteroscopy in the investigation of Infertility. J Obstet and Gynaec India. 1997;(8):807.

20. Sun AD. Laparoscopy for the diagnosis of endometriosis. 1991;26(1):24-7.

21. Kumar AK. Diagnostic laparoscopy in the evaluation of female factor infertility Int J Reprod Contracept Obstet Gynecol. 2017;6(2):383-7.

Cite this article as: Rekha N, Patil SB. Evaluation of various factors in secondary infertility by diagnostic laparoscopy. Int J Reprod Contracept Obstet Gynecol 2017;6:1972-7. 